F.V. Rokhlina1, G.A. Novik, N.M. Kalinina ${ }^{2}$, N.V. Bychkova², Y.N. Filippova², M.I. Zarayskiy $^{3}$

${ }^{1}$ Saint Petersburg State Pediatric Medical University of the Ministry of Health of Russia, Russian Federation

2 Nikiforov All-Russian center of emergency and radiation medicine of the Ministry of Emergency Situations of Russia, Saint Petersburg, Russian Federation

${ }^{3}$ Pavlov Saint Petersburg State Medical University, Russian Federation

\title{
Influence of C3435T polymorphism of gene MDR1 on the efficacy of juvenile idiopathic arthritis therapy
}

Author affiliation:

Faina Valer'evna Rokhlina, assistant of the Vorontsov pediatrics department of the postgraduate and additional professional education faculty at the SPbSPMU

Address: 2, Litovskaya Str., Saint Petersburg, 194100, tel.: +7 (921) 746-96-82, e-mail: faina.rokhlina@gmail.com

Article received: 14.04.2013, accepted for publication: 30.09.2013.

Juvenile idiopathic arthritis (JIA) is a multifactorial disease: its pathogenesis includes immunological and genetic factors. Gene MDR1 is responsible for resistance to various cytotoxic drugs. Product of gene MDR1 - P-glycoprotein (P-gp) acts as a transmembrane pump, thus affecting action of drugs. The research objective was to determine connection of C3435T polymorphism of gene MDR1 with P-protein's expression level in children with JIA. P-protein was revealed in all the patents involved in our trial: the protein was revealed on peripheral blood lymphocytes before and after stimulation of interleukin 2. The authors also picked out genome DNA using phenol-chloroform extraction and detected C3435T polymorphism of the gene MDR1 using polymerase chain reaction. Methotrexate concentration in blood serum was determined using a standard method of fluorescent polarization (FPIA) using the Abbott apparatus TDxFLx. Statistical manipulation of the data obtained in the course of the trial was conducted using software Statistica 6.0. C3435T polymorphism of gene MDR1 affects therapy efficacy. Determination of both basal and stimulated (in vitro) P-glycoprotein may be used as additional criterion in the evaluation of disease activity.

Keywords: juvenile idiopathic arthritis, P-glycoprotein, multidrug resistance gen, C3435T polymorphism.

Juvenile idiopathic arthritis (JIA) is an autoimmune disease, one of the most widespread chronic diseases in the childhood $[1,2]$. JIA is a multifactor disease; its pathogenesis includes not only immunologic, but also genetic factors. $M D R$ gene (drug resistance gene) family consists of genes MDR1 and MDR2. Gene MDR1 is responsible for resistance to various cytotoxic drugs; gene $M D R 2$ functions remain unknown [3]. Gene MDR1 product is $\mathrm{P}$-glycoprotein (P-gp); this protein acts as a transmembrane pup and affects action of many drugs [4, 5]. P-glycoprotein is localized on chromosome 7q21. Gene MDR1 polymorphism may affect pharmacokinetics of many drugs, e.g. of cytostatic agents, including anti-tumor drugs [6].

In 1976, R.L. Juliano and V. Ling revealed P-glycoprotein in cell lines with multiple drug resistance. C.J. Chen et al. (1986) revealed gene MDR1 (multiple drug resistance) in humans. It is generally accepted that membrane transporters, such as P-gp, play a considerable role in the development of multiple drug resistance (M.M. Gottesman and V. Ling, 2006). P-gp is a typical protein of the ATP-binding cassette (ABC) transporter consisting of 2 halves, each of which contains a transmembrane (TMD) and nucleotide-binding (NBD) sites. Interaction of the P-gp halves is important for molecule functioning and a flexible connection site is required for the proper interaction of the halves and connection of 2 adenosine triphosphate sites $[7,8]$. 
P-glycoprotein - a gene MDR1-encoded protein - is an important "transporter" for many drugs and is connected with many immunological processes and apoptosis [4]. It is well-known that C3435T polymorphism correlates with P-glycoprotein's activity. A. Pawlik et al. conducted a trial aimed at evaluating C4345T polymorphism of gene MDR1 in adult patients with rheumatoid arthritis and a study of possible correlations of susceptibility to disease with disease activity. The spread is as follows: $3435 \mathrm{CC}-25(26.9 \%), 3435 \mathrm{CT}-50(53.8 \%), 3435 \mathrm{~T}-17(18.3 \%)$ cases. Spread of C3435T MDR1 genotypes in patients with rheumatoid arthritis (RA) did not differ significantly from the spread in the control group. According to this trial, risk of remission of RA symptoms in the patients receiving methotrexate and glucocorticosteroids is 2.89 times higher in the patients with TT genotype than in the patients with CC and CT genotypes [9].

J. Chen studied adults with rheumatoid arthritis in a Chinese population in order to determine whether the multiple drug resistance gene (MDR1) is connected with refractory rheumatoid arthritis (RRA). The trial involved 223 patients with rheumatoid arthritis receiving treatment and 103 healthy people (control group). RA patients were divided into 2 groups on the basis of response to the antirheumatic therapy (DMARDs). The first group consisted of 108 patients receiving therapy with positive effect, the second - of 115 patients with RA, in whom the therapy did not yield any positive results. C3435T polymorphism genotypes were determined by polymerase chain reaction (PCR). The trial revealed that C3435T MDR1-genic polymorphism may affect RA therapy DMARDs efficacy. There is a correlation between CC genotype of gene MDR1 and unresponsiveness to RA therapy [10].

M. Cizmarikova et al. studied this polymorphism (C3435T) in patients with breast cancer. Evaluation of MDR1 genotype and allele frequency (C3435T polymorphism) in patients with breast cancer (221 people) and healthy participants (113 people) showed that allele $\mathrm{T}$ is more often observed in the group of patients. Results of this trial confirmed the hypothesis that Tallele is usually associated with lower MDR1 expression and reduction in the P-gp function, thus maintaining worse protection of cells [11].

On the other hand, increase P-gp expression was revealed in the epileptics resistant to the conducted therapy. Presence of CC genotype of gene MDR1 in epileptics was accompanied by higher P-gp level; probably, this was the cause of formation of resistance to antiepileptic therapy [12].

A study of adult patients with rheumatoid arthritis receiving methotrexate (MTX) therapy in the dose of $4-10 \mathrm{mg} / \mathrm{m}^{2}$ was conducted in Japan in 2012. It was aimed at determining connection between MTX concentration and therapy efficacy. The correlation analysis did not reveal any connection between MTX concentration (in erythrocytes) and activity parameters (DAS28, ESR, CRP). C3435T polymorphism of gene MDR1 was established in all 55 patients participating in the study; it appeared that disease activity score DAS28 in the patients with TT genotype was significantly lower than in the patients with CC genotype; this indicates direct influence of C3435T polymorphism of gene MDR1 on the MTX monotherapy efficacy [13].

Despite numerous trials dedicated to the study of gene MDR1 polymorphism, the results remain inconsistent, which is why further research dedicated to the study of drug resistance formation mechanism in children is required.

The aim of our trial was to determine connection of $\mathrm{C} 34535 \mathrm{~T}$ polymorphism of gene MDR1 with the level of P-protein expression in the children with JIA receiving baseline methotrexate therapy.

\section{STUDY METHODS}

Our trial involved 103 children with different (according to the ILAR classification) forms of JIA. Polyarticular JIA was the most widespread among the patients - 46 cases $(44.66 \%)$; oligoarticular JIA was observed in 25 cases (24.27\%), systemic - in 14 cases (13.59\%), enthesitis-associated - in 18 cases $(17.48 \%)$. The compulsory inclusion condition was the age 
less than 17 years at the disease onset and at least 3 months of baseline MTX therapy (intramuscularly) in the dose of $15 \mathrm{mg} / \mathrm{m}^{2}$ by blood sampling.

Molecular-genetic research (C3435T polymorphism of gene MDR1 and identification of Pglycoprotein) was conducted in the control group represented by 26 conditionally healthy children under 17 years of age.

Apart from the routine study methods (examination of patients, evaluation of articular status, biochemical activity parameters), we also identified P-protein in all the patients [the protein was revealed on the peripheral blood lymphocytes before and after stimulation of interleukin (IL) 2]. In order to determine the relevant amount of lymphocytes carrying MDR-receptors on their membranes, heparinized peripheral blood cells were stained by the antibodies to CD 243-PE (Beckman-Coulter, USA) after a 3-hours-long incubation at $37^{\circ} \mathrm{C}$ in the $5 \% \mathrm{CO} 2$ atmosphere with and without $5 \mathrm{mcl}$ of roncoleukin (recombinant human interleukin 2, 1,000,000 IU, LLC "BIOTECH", Russia) in compliance with the manufacturer's instructions. We used the peripheral blood cells unstained by antibodies as negative control. Immunophenotyping of the peripheral blood cells was conducted by means of flow cytometry using CXP software (Cytomics FC500, Beckman-Coulter, USA), no-clean technology using OptiLyse C (BeckmanCoulter, USA) for erythrocyte lysis. We analyzed 5,000 events in the lymphocyte gate distinguished on the basis of straight and lateral light scattering parameters.

We also isolated genome DNA from blood of all the patients by phenol chloroform extraction and determined C3435T polymorphism of gene MDR1 by means of PCR. Amplification was conducted using device ICycler (BioRad, USA) according to the biprimer scheme in the final volume of $15 \mathrm{mcl}$ with SYBR Green I stain. Each sample was amplified in 2 different test tubes containing one common reverse primer 5'- actataggccagagaggctgc-3' and, separately, 2 forward primers for both allele variants of gene MDR1: 5'-gtggtgtcacaggaagaggtC-3' and 5'gtggtgtcacaggaagaggtT-3'. Amplification program consisted of initial denaturation $\left(95^{\circ} \mathrm{C}, 3\right.$ minutes) and 40 cycles including denaturation $\left(94^{\circ} \mathrm{C}, 20\right.$ seconds) and primer annealing + elongation $\left(6^{\circ} \mathrm{C}, 40\right.$ seconds).

Blood serum MTX concentration was determined by a standard method - fluorescence polarization (FPIA) using device TDxFLx (Abbott). This analysis uses marker fluorescein. The FPIA reaction involves the antigen identifiable in biologic fluid, antigen conjugate with the marker - fluorescein - and the antibodies specific to them. Accurate correlation of polarization intensity and substance concentration is determined by means of a calibration schedule.

Statistical data manipulation was conducted using software Statistica 6.0. Comparative analysis was conducted using the standard Pearson's $\chi^{2}$ (Chi-squared) test and the Fisher's bilateral test (exact test), where $\mathrm{p}<0.01$ was considered statistically significant.

\section{STUDY RESULTS}

The spread by genotypes of C3435 polymorphism of MDR1 in patients with JIA was the same as in the population in whole. The most frequent genotype - CT - was revealed in $58.25 \%$ of children in the group of patients with JIA; the percentage of such children in the control group was $57.69 \%$. $24.27 \%$ and $34.62 \%$ of children in the main group and the control group, respectively, had TT genotype. The least frequent genotype was CC: it was revealed in $17.48 \%$ of patients in the group of patients with JIA and in $7.69 \%$ of children in the control group (pic. $1)$.

Based on the ILAR classification, we distinguished a group of children with oligoarthritis $(n=25)$ among patients with JIA. CT genotype was identified in the patients with this disease in the vast majority of cases $(80 \%)$. In the group of children with polyarthritis $(n=46), 21(45.6 \%)$ children had CT genotype, $13(28.3 \%)$ - TT genotype, $12(26.1 \%)$ - CC genotype. CT genotype was revealed in half of the patients with systemic JIA $(n=14)$. In patients with enthesitis-associated arthritis $(\mathrm{n}=18)$, CT genotype was identified in $12(66.7 \%)$ children, TT genotype - in $5(27.7 \%)$, CC genotype - only in $1(5.6 \%)$ (pic. 2$)$. 
Pic. 1. Spread by genotypes of C3435T polymorphism of gene MDR1 in the JIA patients and the control group.

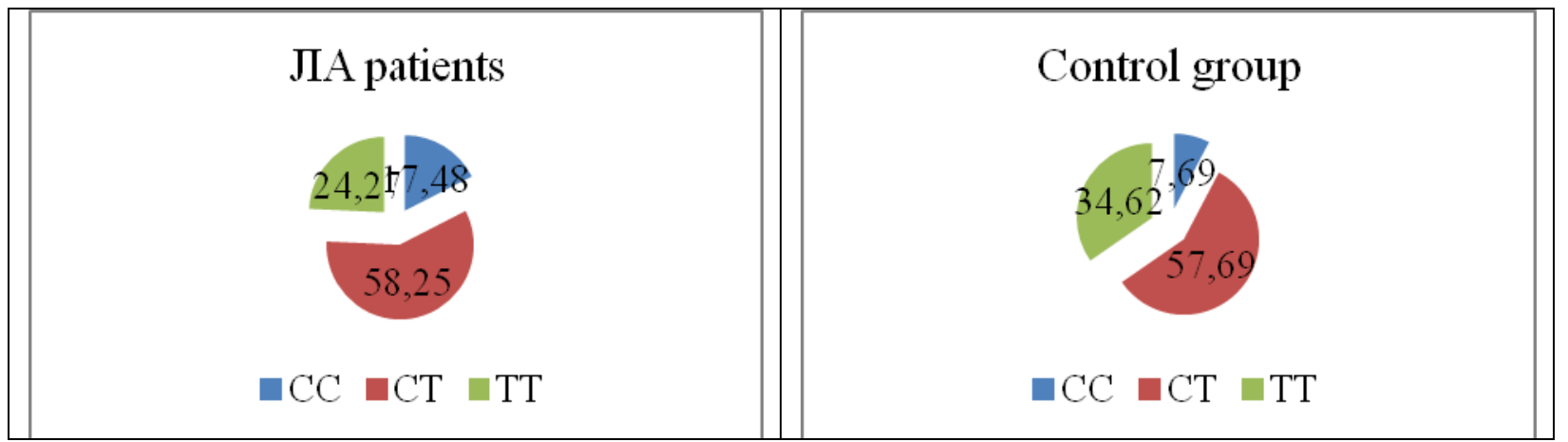

Pic. 2. Spread of genotypes of C3435T polymorphism of gene MDR1 among JIA patients; based on the ILAR classification.

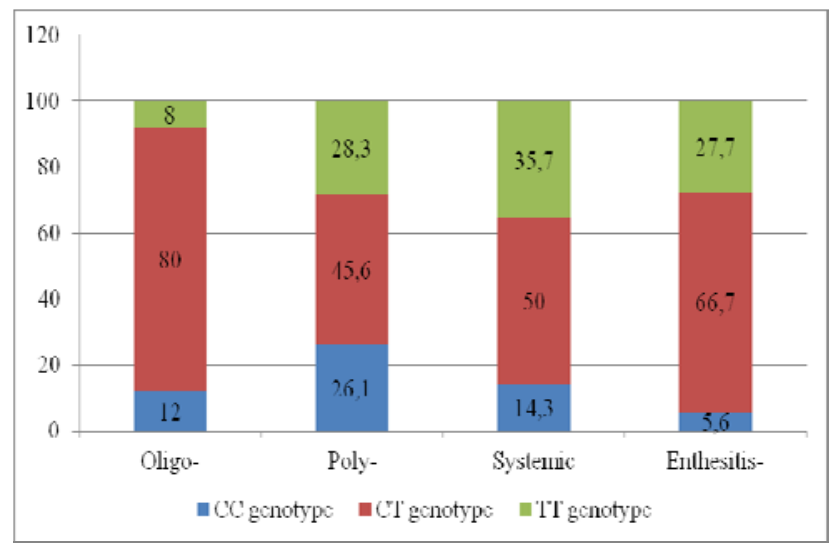

We examined 103 children - 65 (63.1\%) girls and 38 (36.9\%) boys. 60 children had CT genotype -23 boys $(38.3 \%)$ and $37(61.7 \%)$ girls. The group of patients with the rarer TT genotype was represented by $15(60 \%)$ girls and $10(40 \%)$ boys. 18 patients had CC genotype $13(72.2 \%)$ girls and $5(27.8 \%)$ boys (pic. 3$)$.

Pic. 3. Spread of genotypes of C3435T polymorphism of gene MDR1 by sex in JIA patients.

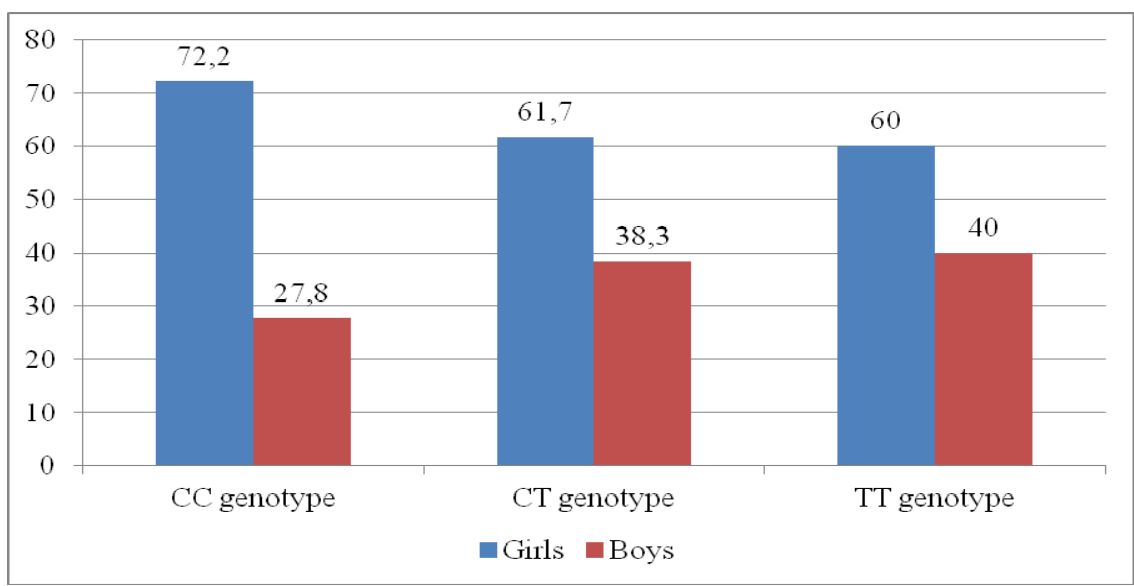

Such parameters as erythrocyte sedimentation rate (ESR) and C-reactive protein (CRP) are used to evaluate activity of juvenile idiopathic arthritis [14]. We observed a statistically significant 
ESR increase in the group of patients with TT genotype. It might be mentioned that the CRP level was higher in the patients carrying $\mathrm{T}$ allele (tb. 1).

It is well-known that the gamma-globulin fraction of serum proteins increases in patients with autoimmune diseases. The gamma-globulin level in the group of children with JIA was statistically significantly higher in boys with CT genotype than in girls with TT genotype and lower than in girls with CC genotype (tb. 2).

Table 1. JIA activity parameters in the examined group on the basis of C3435T polymorphism of gene MDR1.

\begin{tabular}{|l|l|l|l|l|}
\hline Patients & CC genotype & CT genotype & TT genotype & Significance \\
\hline Parameter & 1 & 2 & 3 & \\
\hline ESR $(\mathrm{mm} / \mathrm{h})$ & $11.3 \pm 2.5$ & $12.2 \pm 1.44$ & $18.72 \pm 3.6$ & $\mathrm{p}_{2-3}=0.04$ \\
\hline CRP $(\mathrm{mg} / \mathrm{l})$ & $4.6 \pm 2.1$ & $11.2 \pm 2.64$ & $12.2 \pm 4.9$ & $\mathrm{p}>0.05$ \\
\hline
\end{tabular}

Table 2. Blood serum gamma-globulin level in girls with JIA on the basis of C3435T polymorphism of gene MDR1.

\begin{tabular}{|l|l|l|l|l|}
\hline Patients & CC genotype & CT genotype & TT genotype & Significance \\
\hline Parameter & 1 & 2 & 3 & \\
\hline Blood serum gamma-globulins & $22.55 \pm 1.23$ & $21.59 \pm 0.69$ & $19.04 \pm 0.9$ & $\begin{array}{l}\mathrm{p}_{1-2}=0.04 \\
\mathrm{p}_{2-3}=0.023\end{array}$ \\
\hline
\end{tabular}

We distinguished between groups of patients with active and inactive disease stage on the basis of the inactive disease criteria developed by Carol A. Wallace et al. Inactive disease means no joints with active arthritis, no fever, rash, serositis, splenomegaly or JIA-associated generalized lymphadenopathy, no exacerbation of uveitis, normal ESR and CRP levels [15].

We discovered that the average P-protein level in children with active disease (both before and after stimulation of IL 2) was significantly $(p=0.002)$ higher than in children with inactive disease. This P-protein level dynamics indicates that the children with active disease also have a higher activity of gene MDR1, which controls cellular concentration of the cytostatic drug (pic. 4).

Pic. 4. Dependence of P-protein level on stimulation of IL 2 in JIA patients in an active or in an inactive disease stage.

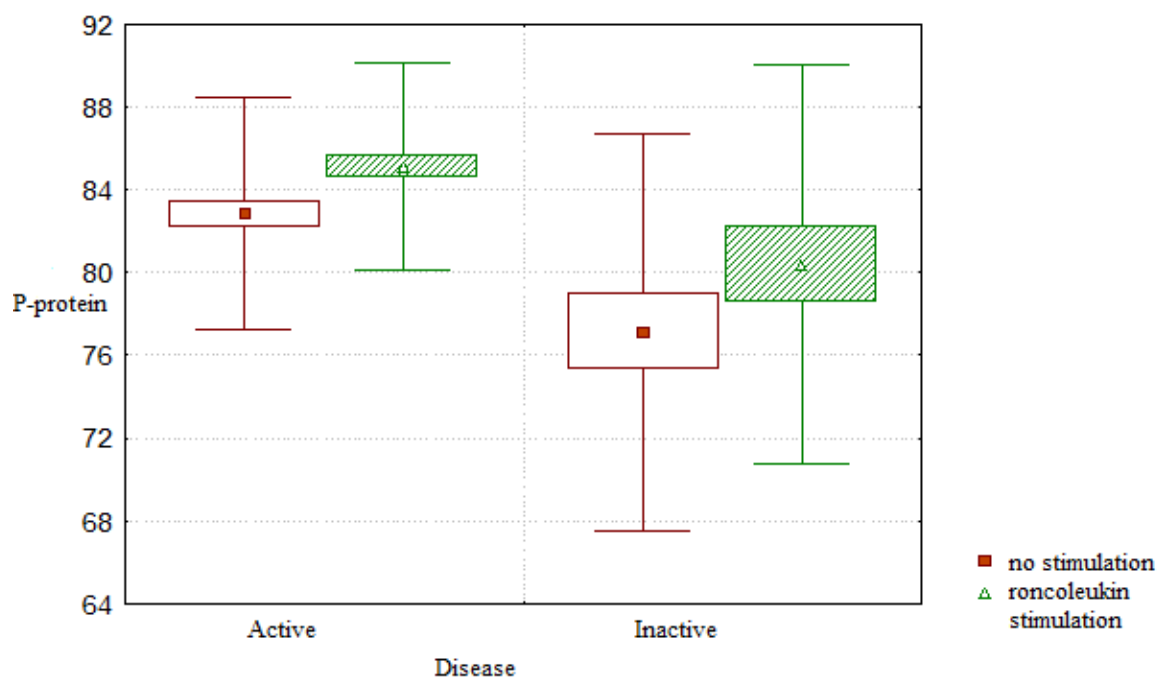


P-protein increment level was significantly lower in the group of children with TT genotype after stimulation of IL 2 than in patients with $\mathrm{CT}$ and $\mathrm{CT}+\mathrm{CC}$ genotypes (tb. 3 ).

Table 3. P-protein level in children with JIA on the basis of C3435T genotype of gene MDR1.

\begin{tabular}{|l|l|l|l|l|l|l|}
\hline & Parameter & CC (n=18) & $\begin{array}{l}\text { CC+CT } \\
(\mathbf{n = 7 8 )}\end{array}$ & CT (n=60) & TT (n=25) & Significance \\
\hline & & 1 & 2 & 3 & 4 & \\
\hline & P-protein level & $83.05 \pm 1.04$ & $81.3 \pm 0.86$ & $80.78 \pm 1.07$ & $81.46 \pm 1.25$ & $\mathrm{p}>0.05$ \\
\hline & $\begin{array}{l}\text { P-protein level after } \\
\text { stimulation } \\
\text { interleukin (IL) 2 of }\end{array}$ & $85.22 \pm 0.96$ & $84.57 \pm 0.58$ & $84.38 \pm 0.7$ & $81.68 \pm 2.06$ & $\mathrm{p}>0.05$ \\
\hline $\begin{array}{l}\text { P-protein increment } \\
\text { after stimulation of } \\
\text { IL 2 }\end{array}$ & $2.17 \pm 1.04$ & $3.273 \pm 0.712$ & $3.603 \pm 0.870$ & $0.22 \pm 1.512$ & $\begin{array}{l}\mathrm{p}_{2-4}=0.047 \\
\mathrm{p}_{3-4}=0.045\end{array}$ \\
\hline
\end{tabular}

At the same time, P-protein level after stimulation of IL 2 was significantly lower in boys with TT genotype than in boys with CC and CT genotypes (tb. 4).

Table 4. P-protein level (after stimulation of IL 2) in boys with JIA on the basis of C3435T genotype of gene MDR1.

\begin{tabular}{|l|l|l|l|l|}
\hline Genotype & CT genotype & TT genotype & CC genotype & Significance \\
\cline { 1 - 4 } Parameter & 1 & 2 & 3 & \\
\hline Number of patients & 23 & 10 & 5 & \\
\hline P-protein after stimulation of IL 2 & $85.19 \pm 1.18$ & $81.09 \pm 1.85$ & $88.9 \pm 0.93$ & $\begin{array}{l}\mathrm{p}_{1-2}=0.05 \\
\mathrm{p}_{2-3}=0.013\end{array}$ \\
\hline
\end{tabular}

Comparative analysis of the group of children with P-protein increment after stimulation of IL 2 and the group of children with no registered increment did not reveal any significant differences in the spread of C3435T polymorphism of gene MDR1 (pic. 5).

Blood serum MTX concentration level in the JIA patients with P-protein level increment after stimulation of IL 2 was significantly lower than in the patients with no registered increment. Alpha-1 and alpha-2 levels of the blood serum globulins' protein fractions were significantly higher in the group of children with no registered P-protein increment after its stimulation (tb. 5).

Pic. 5. Spread of JIA patients by genotypes of C3435T polymorphism of gene MDR1 given the P-protein increment after stimulation of interleukin (IL) 2.

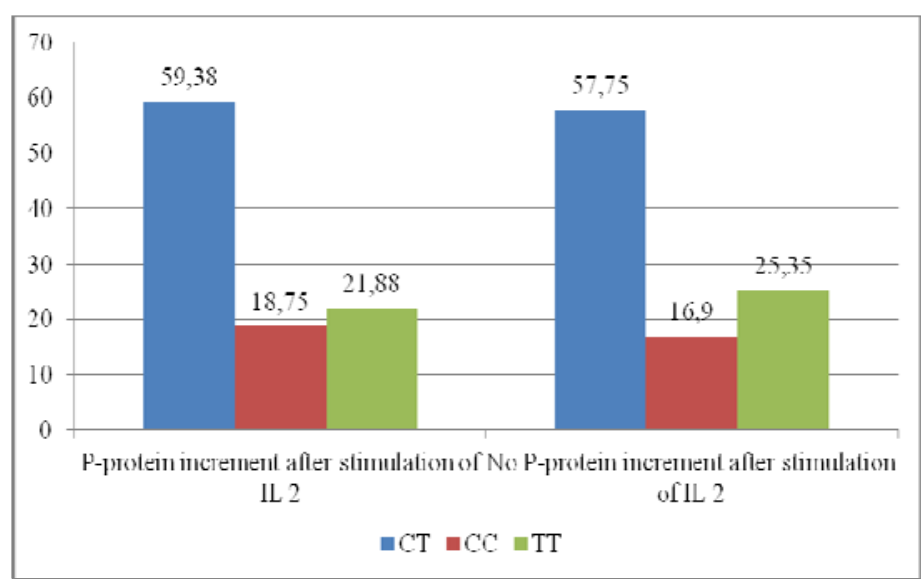


Table 5. Levels of alpha-1,2-globulins and methotrexate concentration in blood serum of JIA patients on the basis of P-protein increment after stimulation of interleukin (IL) 2.

\begin{tabular}{|l|l|l|l|}
\hline P-protein & \multicolumn{2}{|l|}{ P-protein increment after stimulation of IL 2 } & \multirow{2}{*}{ Significance } \\
\cline { 1 - 3 } Parameter & Present & None & \\
\hline Methotrexate concentration & $1.69 \pm 0.076$ & $2.13 \pm 0.275$ & 0.044 \\
\hline Alpha-1-globulins & $4.46 \pm 0.13$ & $5.09 \pm 0.25$ & 0.015 \\
\hline Alpha-2-globulins & $14.09 \pm 0.27$ & $15.58 \pm 0.67$ & 0.015 \\
\hline
\end{tabular}

\section{DISCUSSION}

According to the literature, ca. $30 \%$ of patients with JIA require prescription of additional genetically engineered therapy due to inefficacy of the baseline therapy [16]. Gene MDR1 is responsible for the concentration of cytostatic drugs (in patients with arthritis as well) and may affect efficacy and the patient's responsiveness to the conducted therapy $[6,10]$.

According to our data, no significant differences in the spread of C3435T polymorphism alleles of gene MDR1 in both children with JIA and the conditionally healthy were revealed.

TT genotype implies higher disease activity. Blood serum gamma-globulin level was significantly higher in girls; ESR level - in the children with JIA and TT genotype, regardless of sex.

It is widely known that P-glycoprotein - product of gene MDR1 - functions as a pump, evacuating cytostatic drug from cells; it may result in the lack of effect of the conducted therapy [8].

In our trial, we followed the method of determining P-gp level before and after stimulation of lymphocytic suspension's IL 2 with determination of the percentage of cells carrying P-protein. The previously conducted trials on cell cultures clearly showed the role of IL 2 as of a growth factor for lymphocytes and stimulants of their functional activity. IL 2 is responsible for the in vivo differentiation of T-regulatory lymphocytes, actively participating in formation of autoimmune and systemic diseases [17].

According to the data obtained during the trial, P-gp increase (basal level, stimulated IL 2) was revealed in all the patients meeting active JIA criteria than in patients with inactive disease. Despite the marked P-gp increment after processing of IL 2 lymphocytes (in vitro), several children with JIA had lower blood serum MTX concentration than the other children with JIA. These data indicate the existence of various (not only MDR1 activity) mechanisms affecting formation of the therapeutic concentration of cytostatic drugs in blood. Snap determination of blood serum methotrexate concentration is ineffective and does not allow using this parameter to decide whether to change therapy of patients with JIA or not. Our data confirmed the results of our Japanese colleagues, who were unable to establish connection of erythrocyte methotrexate concentration with effect of the conducted therapy in adult patients with rheumatoid arthritis.

\section{CONCLUSION}

C3434T polymorphism of gene MDR1 affects therapy efficacy. The disease may take a more active course in the JIA patients with TT genotype than in the children with CC and CT genotypes.

Determination of both basal and stimulated (in vitro) P-glycoprotein in lymphocytic suspension may be used as an additional objective criterion of active/inactive disease stage in JIA patients. 


\section{REFERENCES}

1. Harris J. G., Kessler E. A., Verbsky J. W. Update on the Treatment of Juvenile Idiopathic Arthritis. Curr Allergy Asthma Rep. 2013; 13: 337-346.

2. Bulatovic M., Heijstek M. W., Verkaaik M. et al. High Prevalence of Methotrexate Intolerance in Juvenile Idiopathic Arthritis. Art Rheumat. 2011; 63 (7): 2007-2013.

3. Chin J. E., Soffir R., Noonan K. E. et al. Structure and Expression of the Human MDR (PGlycoprotein) Gene Family. Molecular and cellular biology. 1989. P. 3808-3820.

4. Mironova Zh. A., Trofimov V. I., Simakova M. A. et al. Rossiiskii allergologicheskii zhurnal - Russian allergological journal. 2010; 3: 9-13.

5. Annese V., Valvano M. R., Palmieri O. et al. World Multidrug resistance 1 gene in inflammatory bowel disease: A Meta-analysis. J Gastroenterol. 2006 June 21; 12 (23): 36363644 .

6. Ambudkar S. V., Kimchi-Sarfaty C., Sauna Z. E. et al. P-glycoprotein: from genomics to mechanism. Oncogene. 2003; 22: 7468-7485.

7. Cantarini L., Simonini G., Frediani B. et al. Treatment strategies for childhood noninfectious chronic uveitis: an update. Expert Opin Investig Drugs. 2012; 21 (1).

8. Sauna Z. E., Kim I.-W., Ambudkar S.V.J Genomics and the mechanism of P-glycoprotein (ABCB1). Bioenerg Biomembr. 2007; 39: 481-487.

9. Pawlik A., Wrzesniewska J., Fiedorowicz-Fabrycy I. et al. The MDR1 3435 polymorphism in patients with rheumatoid arthritis. Int J Clin Pharmacol Ther. 2004 Sep; 42 (9): 496-503.

10. Chen J., Chen L., Mao N. et al. Association of the MDR1 3435 polymorphism in patients with refractory rheumatoid arthritis in a Chinese population. Rheumatol Int. 2011.

11. Cizmarikova M., Wagnerova M., Schonova L. et al. MDR1 (C3435T) polymorphism: relation to the risk of breast cancer and therapeutic outcome. The Pharmacogenomics Journal. 2010; 10: 62-69.

12. Sills G. J., Mohanraj R., Butler E. et al. Lack of Association between the C3435T

Polymorphism in the Human Multidrug Resistance (MDR1) Gene and Response to Antiepileptic Drug Treatment. Epilepsia. 2005; 46 (5): 643-647.

13. Kato T., Hamada A., Mori S. et al. Genetic Polymorphisms in Metabolicand Cellular Transport Pathway of Methotrexate Impact Clinical Outcome of Methotrexate Monotherapy in Japanese patients with Rheumatoid Arthritis. Drug Metab Pharmacokinet. 2012; 27 (2): 192199.

14. Jaap F., Stucki G., Piet L. C. M. van Riel. Rheumatoid Arthritis Measures Disease Activity Score (DAS), Disease Activity Score-28 (DAS28), Rapid Assessment of Disease Activity in Rheumatology (RADAR), and Rheumatoid Arthritis Disease Activity Index (RADAI). Arthritis \& Rheumatism (Arthritis Care \& Research). 2003 Oct. 15; 49 (5): S214-S224. Doi 10.1002/art.11407 C 2003, American College of Rheumatology.

15. Wallace C. A. Current management of juvenile idiopathic arthritis. Best Practice \& Research Clinical Rheumatology. 2006. P. 279-300.

16. Foeldvari I., Wierk A. Effectiveness of Leflunomide in Patients with Juvenile Idiopathic Arthritis in Clinical Practice. J Rheumatol. 2010. pp. 1763-1767.

17. Ketlinskii S. A., Simbirtsev A. S. Tsitokiny [Cytokines]. St. Petersburg, «Izdatel'stvo Foliant» LLC, 2008. pp. 267-278. 